Meta

Journal des traducteurs

Translators' Journal

\title{
Discourse Theory and Performance-Based Assessment: Two Tools for Professional Interpreting
}

\section{Andrew Clifford}

Volume 46, numéro 2, juin 2001

Évaluation : paramètres, méthodes, aspects pédagogiques /

Evaluation: Parameters, Methods, Pedagogical Aspects

URI : https://id.erudit.org/iderudit/002345ar

DOI : https://doi.org/10.7202/002345ar

Aller au sommaire du numéro

Éditeur(s)

Les Presses de l'Université de Montréal

ISSN

0026-0452 (imprimé)

1492-1421 (numérique)

Découvrir la revue

Citer cet article

Clifford, A. (2001). Discourse Theory and Performance-Based Assessment: Two Tools for Professional Interpreting. Meta, 46(2), 365-378.

https://doi.org/10.7202/002345ar
Résumé de l'article

Dans cet article, l'auteur expose les limites d'une approche lexico-sémantique en interprétation. À l'aide de la théorie du discours, il identifie certaines compétences nécessaires à l'interprétation et il propose l'élaboration d'un instrument d'évaluation basé sur la rigueur technique apportée à d'autres professions. L'auteur démontre également comment les éléments discursifs dans une situation d'interprétation peuvent servir de compétences dans une grille descriptive de niveaux de rendement. 


\title{
Discourse Theory and Performance-Based Assessment: Two Tools for Professional Interpreting
}

\author{
ANDREW CLIFFORD \\ University of Ottawa, Ottawa, Canada
}

\begin{abstract}
RÉSUMÉ
Dans cet article, l'auteur expose les limites d'une approche lexico-sémantique en interprétation. À l'aide de la théorie du discours, il identifie certaines compétences nécessaires à l'interprétation et il propose l'élaboration d'un instrument d'évaluation basé sur la rigueur technique apportée à d'autres professions. L'auteur démontre également comment les éléments discursifs dans une situation d'interprétation peuvent servir de compétences dans une grille descriptive de niveaux de rendement.
\end{abstract}

\section{ABSTRACT}

This article examines interpreter assessment and draws attention to the limits of a lexico-semantic approach. It proposes using features of discourse theory to identify some of the competencies needed to interpret and suggests developing assessment instruments with the technical rigour common in other fields. The author gives examples of discursive features in interpretation and shows how these elements might be used to construct a rubric for assessing interpreter performance.

\section{MOTS-CLÉS/KEYWORDS}

interpretation, discourse theory, assessment instruments, competencies, interpreter's performance

\section{Introduction}

Interest in assessment in the field of interpreting may take a variety of forms. For instance, interpreter training programs may wish to screen applicants before admission. Programs may also wish to assess student interpreters at the end of their studies to determine if they are ready for the demands of the job market. Working interpreters may want to assess their own on-the-job performance, or they may want to know how satisfied clients are with their services. Perhaps the most common reason for assessing interpreters is for professional certification.

In jurisdictions all around the world, professional associations of interpreters design and implement certification exams that are intended to identify which interpreters demonstrate the skills needed to meet rigorous professional standards. This article focusses on interpreter certification and argues that a view of interpreting limited to lexico-semantic concerns, as evidenced in student work and existing assessment systems, is inadequate. It points to discourse theory as a means of developing a more complete view of the competencies needed by interpreters, and it underlines the importance of addressing technical measurement principles common in the assessment of other professions. At the end of the article, there is an assessment 
rubric-one example of the ways in which discourse theory could be used to produce an actual assessment instrument.

\subsection{Justification for the Term Professional Interpreting}

For the purposes of this discussion, the term professional interpreting is used to refer to two modes of oral translation-conference interpreting (between two spoken languages) and sign language interpreting (between a spoken and a sign language). These two modes, and the professions that have grown up around them, share a number of features. First, they have a common neuropsychological foundation, ${ }^{1}$ which suggests that the cognitive skills involved are similar, if not the same. Second, the recognized professions of conference interpreter and sign language interpreter have only been in existence for a short time. In Canada, the Association of Translators and Interpreters of Ontario (ATIO) was founded in 1920, while the Association of Visual Language Interpreters of Canada (AVLIC) dates from 1980. These dates are recent when compared with the founding of other professional bodies-the College of Physicians and Surgeons of Ontario (Canada) was founded in 1866, and the Law Society of Upper Canada has an even more lengthy history, beginning in 1797 . The differences in founding dates have meant that while other professions have had the time to develop technically rigorous assessment, this is not the case in either mode of interpreting. For these two reasons-similarity of neuropsychological foundation and the brief existence of recognized professions-conference and sign language interpreting are grouped together in this examination of interpreter assessment.

\section{Are Lexico-Semantic Competencies Enough?}

Any assessment of interpreters must determine whether they are competent, that is, whether they have the complex skills-or competencies-needed to meet professional standards. Use of the term competency is founded on two beliefs: 1) the components of a competency interact in an intricate way, and do not work independently of one another; and 2) competencies are strongly linked to context-they must be assessed in a context that resembles the one in which they were acquired (Resnick and Resnick 1992).

This definition begs an obvious question: what are the competencies that need to be assessed in professional interpreting? If we are going to certify interpreters, we will need to determine which competencies we should target in our assessment. Before doing so, however, we will first need to address a weakness that frequently characterizes thinking about the act of translation.

The general population often has a simplified understanding of what it means to translate. They perceive translation as a kind of lexico-semantic exercise, an act carried out on language form that requires a one-to-one substitution of target language lexical items for the lexical items of the source language. Student interpreters, who come to training programs from the general population (sometimes via studies in written translation, hence the inclusion of some of the examples below), carry these reductive perceptions with them. As a result, interpreting, as an oral form of the act of translation, is often seen as a lexico-semantic task. 


\subsection{Evidence from Student Translation}

Table 1 outlines a number of examples where the reductive perception of translation is at work. These examples are of interest because they demonstrate the lexicosemantic tendency at three levels - the level of the word, the phrase and the fixed expression. In each case the size of the linguistic sign is different, but the processthe substitution of target language forms for source language forms-is the same.

In the first example, Folkart (1988) illustrates the dangers of translating at the word level. She notes an instance where a student successfully translates the plural French connaissances into the singular English knowledge. A few sentences later, however, the student comes across the pronoun les, and seemingly forgets both the noun to which it refers and how this noun was previously translated into English. The resulting lack of coherence in the English translation is problematic.

In the second example, Seleskovitch and Lederer (1984) ably demonstrate how translation at the phrase level can lead students into difficulty. They break the English sentence "It's all right to get a bit drunk at a party" into phrases and ask their students to translate each phrase. Reassembling the translated phrases, they wind up with a French sentence- “ça va de s'enivrer un peu lors d'une réception”- which they argue is not only unidiomatic, but may even impede comprehension.

The third example (Bensimon 1994) shows how Heaney's poem Casualty uses a fixed expression, to drink like a fish, to tell the story of an Irish fisherman's death in an IRA bomb attack. The French translator chooses an equivalent expression-boire comme une éponge-which is able to successfully incorporate the maritime theme. However, an examination of the entire stanza shows that this expression is an unfortunate choice, since the image of a sponge swimming towards bait does not conjure as effective an image in the mind of the reader as the original source language expression.

TABLE 1

Lexico-Semantic Translation at Three Levels

\begin{tabular}{|c|c|}
\hline $\begin{array}{l}\text { 1. Word Level } \\
\text { acquérir des connaissances dans } \\
\text { une spécialité } \\
\text { les gérer et les structurer }\end{array}$ & $\begin{array}{l}\text { gain knowledge in a specific field } \\
\text { manage and structure them }\end{array}$ \\
\hline $\begin{array}{l}\text { 2. Phrase Level } \\
\text { it's all right } \\
\text { a bit } \\
\text { to get drunk } \\
\text { a party } \\
\text { It's all right to get a bit drunk } \\
\text { at a party. }\end{array}$ & $\begin{array}{l}\text { ça va } \\
\text { un peu } \\
\text { s'enivrer } \\
\text { une réception } \\
\text { Ça va de s'enivrer un peu lors d'une réception. }\end{array}$ \\
\hline $\begin{array}{l}\text { 3. Fixed Expression } \\
\text { Excerpt from Casualty } \\
\text { by Seamus Heaney } \\
\text { He had gone miles away } \\
\text { For he drank like a fish } \\
\text { Nightly, naturally } \\
\text { Swimming towards the lure } \\
\text { Of warm lit-up places [...] (v. 70-74) }\end{array}$ & $\begin{array}{l}\text { Translation by Anne Bernard Kearney } \\
\text { Il s'était bien éloigné } \\
\text { Car il buvait comme une éponge } \\
\text { Tous les soirs, nageant } \\
\text { Naturellement ver l'appât } \\
\text { Des endroits chauds et bien éclairés [...] }\end{array}$ \\
\hline
\end{tabular}


In each of these examples, the translators encounter difficulty with meaning and its location. They seem to see their source texts as nothing more than a linear string of linguistic signs (of varying sizes) and the act of translation as nothing more than substitution of target language signs for the signs of the source language.

\section{Discursive Competencies}

Interpreters do need to be concerned with lexicon (particularly when dealing with technical terminology and proper nouns), but this is only a part of their work. In the same way that Saussure (1969) suggested that the linguistic sign is comprised of the signifier and the signified, the work of professional interpreters is made up of an énoncé, or utterance, and an énonciation, the act of uttering as it is produced and received in a particular socio-cultural context. To limit our understanding of interpreting to lexico-semantic concerns, is to focus solely on the énoncé and ignore the énonciation. In order to assess interpreter's competencies in context, we must include both parts together. We must learn to see interpreting as a form of discourse.

One way in which discourse theory is of benefit to interpreting assessment is in its explanation of meaning. The lexico-semantic model holds that meaning is "in the words" and suggests that if we translate a string of lexical items, of varying sizes, meaning will take care of itself. Yet, as the examples in Table 1 show, this approach does not always give satisfactory results. To understand interpreting as a form of discourse means understanding that meaning, in fact, comes from three sources: the features of the utterance itself (as in the lexico-semantic model), the utterer's intent and the receiver's interpretation (Eco 1982). These three sources interact with one another. Utterer and receiver make use of language to produce and understand meaning through the utterance. In turn, this language use shows traces of both utterer and receiver in a number of its features. In the pages that follow, there is an examination of three of these features. Deixis, modality and speech acts are first explained in a general sense, and then there is a discussion of their usefulness to the understanding of meaning, and consequently to interpreter assessment.

\subsection{Deixis}

All known languages have subjective forms that do not behave as lexical entities (Benveniste 1971). Words such as "I" and "you" cannot be defined as other lexical items are; there is no overarching concept of "I" that includes all possible "I's." Instead, our understanding of "I" depends on our knowledge of who is speaking in a given setting, to whom, where and when. The same is true for words such as "here" and "now." Subjective forms that depend on context for definition are known collectively as deixis (O’Grady \& Dobrovolsky 1992).

In oral communication, speakers may speak from their own point of view, as well as from viewpoints of others. On a semantic level, a speech may contain one true semantic deictic, the "I" of the speaker (e.g., "I believe this matter is of grave importance..."), which designates his or her point of view, in addition to a number of points of view attributed to third person references (e.g., "...on the other hand, he seems to believe the matter can be taken quite lightly...”). In such communication, it is relatively easy for the interpreter to follow the shifting of roles between these 
different voices, as they are quite clearly identified through the use of first-person and third-person pronouns.

However, oral communication will often make identifying a role shift more difficult when the speaker decides to express all the varying points of view in the first person (Ong 1982). ${ }^{2}$ This is also a grammatical feature in sign languages such as American Sign Language (ASL). When the people producing an utterance role shift express different viewpoints from a first person perspective, interpreters can no longer rely solely on grammar to make sense of the utterance. Instead, they need to pay careful attention to other suprasegmental features (see below) to help them identify role shifts.

\subsection{Modality}

A second feature of discourse that is germane to the act of interpreting is modality. Through modality, people express an attitude about their own utterances. For example, an utterer may, depending on intonation, express a degree of uncertainty in a sentence like, "I think it will rain today." Rather than being a statement that only gives information about exterior, neutral events, the sentence gives us a sense of how the utterer feels about what has been said. For the purposes of this article, let us extend the definition of modality to include argumentation. When constructing an argument, utterers also give information about themselves, since they are indicating their position on a topic and perhaps even making an effort to win the receiver of the utterance over to their point of view. A series of argumentative utterances is steered in a particular direction by an internal conclusion, a conclusion that is chosen in advance by the speaker (Ducrot 1980).

It is important for interpreters to realize that the links utterers create between units of information are motivated by this internal conclusion (Ducrot 1980). As a result, an interpretation should not be the simple list of featureless target language equivalents: the argumentative direction the source language utterer embarks on should be maintained and reproduced in the target language. In a promotional sentence like, "Buy and Save!" the relationship between the ideas is not simply additive as it most often is with and (compare with "I like dogs and cats"). The relationship is one of causality-saving is the result of buying (Delisle 1980). ${ }^{3}$ The utterer of this sentence is making a statement, the meaning of which does not derive from the words themselves ("and" does not necessarily convey causality), but rather from the rhetorical position of the utterer in this particular setting (advertising executives speaking on behalf of a retail client) and who they are addressing (potential customers of the retail client).

This kind of argumentative analysis is easy in hindsight. It is quite another matter to arrive at this level of understanding during consecutive or even simultaneous interpretation. Happily, oral communication provides the interpreter with another feature, besides grammar, that helps in identifying the argumentative direction of a speaker-prosody. ${ }^{4}$ Halliday (1970: 21) argues that intonation provides more than expressive meaning at the sentential and intersentential levels:

The importance of intonation is not so much that it is a part of a good accent, or of the right way of speaking, although it is true, of course, that a good pronunciation always includes correct intonation as well as correct articulation and rhythm. The importance 
of intonation is also that it is a means of saying different things. If you change the intonation of a sentence you change its meaning.

The connections between units of information in oral discourse are made both at the level of syntax and at the level of prosody. When speakers offer additional information, contrasting information, or an example or illustration, these decisionsthis argumentative direction - can be heard in the intonational contour speakers give to their utterances. Interpreters must be trained to recognize these contours, understand how they convey an argument, and reproduce an equivalent structure in the target language.

\subsection{Speech Acts}

A third feature of discourse that is important to interpreting is what discourse theory refers to as speech acts. When we view discourse as a speech act, we are paying attention to the reaction that an utterer seeks to elicit with an utterance. When we produce an utterance, we may have any number of intentions - to persuade, to convince, to question, to promise or to threaten. Interpreters must of course be aware of a speaker's use of discourse as a speech act, but they must also understand that the interpretation itself is also a speech act.

Interpreter trainers often encourage their students to "sell" an interpretation, to convince clients that it is a worthy product. In other words, interpreters must try to create a high degree of correspondence between the utterer's contextualization of the source language utterance and their own performance and contextualization in the target language. One of the ways that they do this is by presenting information in a manner that is consistent with the expectations of the target language receivers, expectations that are created by the effect of society and culture on language.

A number of authors have written about this aspect of translation and interpreting. Nord (1997) notes that translators need to produce texts that are meaningful to the target language receivers and that conform to a certain coherence. This coherence, she explains, further dictates that a translation should be understandable and should make sense in the receiving culture and situation. Mindess (1995) provides a practical example of how receiver expectations affect interpreting. She tells of a hearing doctor who asks a Deaf ${ }^{5}$ patient how many hours of exercise he gets per week. The doctor expects a summary response-a number of hours-without contextual information. When the Deaf patient responds with "Well, Monday I went bowling, Tuesday I was sick, Wednesday I was supposed to play softball but I had to help my friend John with his car, Thursday..." he may have frustrated the doctor, but his answer is consistent with Deaf cultural emphasis on sequential events and contextual detail. She advises the interpreter to actively intervene, perhaps by prefacing the Deaf patient's remarks with a signal that the answer is not in the form the doctor expects by adding "Let's see what happened this week for example..." (1995: 80).

As Mindess points out, members of language communities have expectations about the way discourse should be organized, and this organization is a matter of socio-cultural convention. Obviously, the specific differences will depend on the language pairs in question - in this case, the differences between English and ASL demand that some warning be given to the English speaker who is not familiar with the tendency in ASL to give highly contextualized information-but all interpreters 
need to be aware of these differences. If an interpretation is focussed only on the énoncé, it can potentially violate receivers' expectations, leading the receivers to form negative opinions about an interpreter's abilities.

Wherever possible, such as during consecutive interpreting, interpreters should attempt to reorganize information to meet target language expectations. But when there are other demands on interpreters' time and attention, such as during simultaneous interpreting, an effort should be made to give some sign that expectations may not be met. In this way, interpreters carry out a speech act, convincing clients of the credibility of the interpretation and meeting clients' idea of quality.

TABLE 2

Three Features of Énonciation as Applied to Interpreting

\begin{tabular}{|l|l|}
\hline Deixis & $\begin{array}{c}\text { - parts of discourse that are can only be defined if we know the context } \\
\text { (I, here, now) } \\
\text { in spoken language and in ASL, various roles can be assumed and } \\
\text { expressed in the first person }\end{array}$ \\
\hline Modality & $\begin{array}{l}\text { - speaker shows a point of view in discourse } \\
\text { - speaker uses features like co-ordination and subordination to construct } \\
\text { an argumentative structure } \\
\text { - prosody and NMS assist interpreters in perceiving and recreating } \\
\text { argumentative structure }\end{array}$ \\
\hline Speech Acts & $\begin{array}{l}\text { - speaker tries to elicit a particular action or result with discourse } \\
\text { - interpretation is a speech act }\end{array}$ \\
& $\begin{array}{l}\text { - interpreters must convince receivers that the interpretation is credible } \\
\text { structures for the target language }\end{array}$ \\
\hline
\end{tabular}

\section{The Limits of Lexico-Semantic Assessment}

The sections above have suggested a few examples of how discourse theory might be used to overcome the tendency to focus solely on lexico-semantic concerns. The examples that are given are in no way meant to be exhaustive; there is clearly much room for further research on the applications of discourse theory to professional interpreting. However, the usefulness of the examples has thus far been limited to general explanation of interpreting as discourse. At this point, what is needed is a clear link between theory and explanation, on one hand, and the development of an actual assessment instrument, on the other. The pages that follow attempt to make this link, first by examining two descriptive systems that have been proposed for assessment purposes by other authors (Barik 1971; Taylor 1994). Table 3 contains examples from Barik and Taylor's respective systems, examples which illustrate how both of these systems have been heavily influenced by a lexico-semantic approach and focus squarely on the énoncé. 
TABLE 3

The Lexico-Semantic Approach in Interpreting Assessments

1. A1: qualifier addition-addition of a qualifier or a qualifying phrase not in the original version

S version: ...ils gardaient tous deux enracinés en eux...

T version: ...they both had deeply rooted within themselves...

2. A2: elaboration addition-addition in the form of an elaboration or other straight addition to the text.

S version: ... je dois rester conscient de ce qui est juste...

T version: ...I must be aware and conscious of what is just and fair... (1971, p. 201)

3. The meaning of the source language (English is interpreted accurately into the target language.

Possible errors

42.A Addition of meaning occurs.

42.B Omission of meaning occurs (e.g. incomplete meaning, nuances are omitted, opposite meaning is conveyed such as omitting negation, thus making the interpretation look affirmative).

\subsection{Barik and Conference Interpreting}

Barik's system - which, despite its age, is cited often in the interpreting literature-is clearly based on the belief that meaning is located at the level of lexicon. The author breaks his instrument down into three sections that describe different types of errors: additions, omissions, and substitutions. Examples 1 and 2 shown in Table 2 are taken from the section on additions.

In the first case, Barik argues that the adverb "deeply" is an addition and, therefore, an error. However, it could be argued that the interpreter included it, not so much to provide additional qualification, but rather to make the text more idiomatic. In English, it may seem odd to construct a sentence using the verb "to root" in the passive without this particular adverb. In terms of lexical frequency, it seems more likely that the two words form a collocation, as the syntagmatic link between them seems strong.

As for the second example, are the additions "and conscious" and "and fair" truly errors, or examples of normative dualism at work? English has a tendency to use synonymous adjectives in couplets, and many translators judiciously suppress one member of such a pair when working from English into French, a language which does not have the same stylistic convention (Van Hoof 1989).

The features of the interpreter's production that Barik has identified here are not arbitrary additions. Both examples serve to make the production more idiomatic, to make it correspond to the expectations of a hypothetical English audience. But Barik's system does not allow for these expectations, but rather it seems to be a oneto-one comparison of lexical items between the source and target languages, and notions of lexical frequency or idiomaticity are not a prominent consideration. 


\subsection{Taylor and Sign Language Interpreting}

The issue of lexico-semantic interpreting is also evident in perceptions of the work sign language interpreters. As Coppack (1992: 37) notes:

Traditionally, sign language interpreters have not been considered people who create texts in their work at all. The work of reproducing what someone says in a visualgestural or vocal-auditive language in another visual-gestural or vocal-auditive language has tended to have been looked upon more or less as a kind of "mechanical" process. A process whereby one selects the appropriate linguistic units as structures in the target language needed to convey the message the sender has wished to convey in his or her own language.

This traditional view posits that interpreting is merely a linguistic exercise, where it is enough to concentrate on issues of content. It holds that meaning is located at the level of lexicon. If interpreters work accurately with "the words," no further attention to meaning is warranted. Traces of this lexico-semantic approach can also be seen in Taylor's (1994) descriptive system for sign language interpreting. In a section that discusses interpreting in general, Taylor notes that there is error when the interpreter has added or omitted "meaning" (example 3 in Table 2 ), yet this meaning is not clearly defined. Rather, it seems monolithic — constant in all situations, and for all people. Discourse theory, as can be seen in the explanation of the three features of énonciation discussed above, holds that meaning is more complex than Taylor's system seems to allow. Meaning is not always constant, because it is in part dependent on the intent of the utterer, the interpretation of the receiver, and the socio-cultural circumstances they find themselves in.

Clearly, Barik and Taylor's systems have reduced interpreting down to the level of content. They seem to focus exclusively on the énoncé, and they neglect énonciation. As we have seen, lexical concerns are certainly one competency that interpreters need to demonstrate, but there are other competencies that are equally vital if interpreters are to meet rigorous professional standards. An interpretation may be completely accurate in its treatment of linguistic content, but it may still fail to "sell" because of its lack of adequate contextualization. The approach to interpreter assessment must be broadened.

\section{Rigorous Assessment}

Part of this broadening means availing ourselves of the work on assessment that has been done in other disciplines. There has been great interest in assessment in the field of education, for obvious reasons, and much of the writing on the topic comes from this field. In a discussion of the cycle of assessment development, Berger and Simon (1995) suggest that there are four steps in the cycle, and that following these steps carefully and rigorously is essential to producing a satisfactory assessment instrument. The four steps of the development cycle are explained in Table 4. 
TABLE 4

Steps in the Assessment Cycle

\begin{tabular}{|l|l|}
\hline Intention & $\begin{array}{l}\text { What is the purpose of the assessment? What is being assessed? } \\
\text { This is arguably the most important step, since it guides all others. }\end{array}$ \\
\hline Measurement & $\begin{array}{l}\text { This step of the cycle includes collection of data (through the administration } \\
\text { of an assessment), as well as organization of the data and marking. }\end{array}$ \\
\hline Judgement & $\begin{array}{l}\text { Judging the value and quality of the data must be done using a common } \\
\text { system for interpretation understood by all assessors. }\end{array}$ \\
\hline Decision & $\begin{array}{l}\text { Fairness and equity of decision making depends on how rigorously the } \\
\text { previous steps were followed }\end{array}$ \\
\hline
\end{tabular}

While it is essential to plan out the assessment cycle, planning alone will not guarantee the technical rigour of an assessment. It is also important to take measures to reduce the risk of error inherent in assessing professional interpreters, which is essentially an act of generalization (Resnick and Resnick 1992). An assessment is merely a sample performance, from which we are trying to judge whether a person's general interpreting skills meet a given professional standard. As is the case in any inference or estimation, there is always a risk that the sample performance does not give an accurate picture of the person's actual skills. Berger and Simon (1995) point out that the field of assessment seeks to adhere to four fundamental principles of evaluation to minimize the possibility of error-validity, reliability, equity and utility. These principles are described briefly in Table 5 below. A related principle-comparability-has also been added because of its importance to interpreter assessment.

TABLE 5

\section{Principles of Quality Assurance in Assessment}

\begin{tabular}{|l|l|}
\hline Validity & $\begin{array}{l}\text { An instrument is valid if it actually measures what it was designed to measure, } \\
\text { that is, if it allows the assessor to make inferences about the targeted compe- } \\
\text { tency. There are different types of validity: e.g. content, construct, predictive, } \\
\text { instructional, consequential (Berger and Simon, 1995). }\end{array}$ \\
\hline Reliability & $\begin{array}{l}\text { An instrument is reliable if it provides stable results from one administration } \\
\text { to another in comparable conditions of use (Berger and Simon, 1995). } \\
\text { Reliability may be verified through such techniques as testing and retesting on } \\
\text { separate occasions, or using alternate forms of a given assessment (Gipps, 1994). }\end{array}$ \\
\hline Equity & $\begin{array}{l}\text { Equity is the principle that instructs assessors to be aware of gaps in perfor- } \\
\text { mance that exist among groups because of differences in familiarity, exposure } \\
\text { and motivation on the tasks of interest (Linn, Baker and Dunbar, 1991). }\end{array}$ \\
\hline Utility & $\begin{array}{l}\text { An assessment may be valid, reliable and equitable, but high cost or unreason- } \\
\text { ably elaborate procedures may prevent its use. The utility of an instrument is } \\
\text { an indication of how practical it is to use it in a given situation. }\end{array}$ \\
\hline Comparability & $\begin{array}{l}\text { There is comparability in an assessment if it is administered consistently, if there } \\
\text { is common understanding of assessment criteria, and if the performance is } \\
\text { evaluated fairly (i.e., with the same rubric by all markers; Gipps, 1994). } \\
\text { Interpreter assessments need to demonstrate comparability across interpreters } \\
\text { with different working languages, across yearly administrations of the assess- } \\
\text { ment, across raters and even between language modes (spoken versus sign } \\
\text { language). }\end{array}$ \\
\hline
\end{tabular}


Because of their importance, these principles are often the subject of much research and discussion in assessment, both as they apply to education and to recognized professions (Smith and Hambleton 1990; Haladyna 1994; LaDuca 1994). However, professional interpreting stands apart from these other professions, in that formal quality assurance is rarely a concern in the small body of writing that exists on interpreter assessment. This is clearly an oversight that needs to be addressed, and there is much room for future research in this area.

\subsection{Performance-Based Assessment and the Construction of a Rubric}

Previous sections of this article have outlined the way in which discourse theory may be used to describe some of the competencies needed to interpret. But discourse also provides a useful means for constructing some of the more practical tools needed to carry out an assessment of professional interpreters. One clear locus of intersection between discourse and assessment arises out of the development of a performancebased assessment.

As opposed to traditional paper-and-pen assessment techniques such as multiple choice and short answer questions, performance-based assessment evaluates behaviour in a realistic context designed to target particular competencies (McDaniel 1994). If a performance-based approach is adopted for devising interpreter assessment, the assessment cycle (as described in Table 4) might look as follows. The intention of the assessment is to evaluate the competencies of professional interpreters in order to certify them. The measurement would be taken through a performance that resembles, as closely as possible, an interpreter's typical working situation. The judgement would be made against a previously defined rubric, which describes different levels of achievement for the identified competencies. Lastly, the decision, whether to certify an interpreter or not, would be made by comparing the level of performance achieved against minimum standards set within the profession.

As an example of one way in which discourse theory might be incorporated into the cycle of a performance-based assessment, Table 6 displays an assessment rubric. The competencies identified in the rubric are the three features of discourse discussed above, and each competency is described at three different levels of performance.

TABLE 6

Performance-Based Assessment Rubric for Interpreting

\begin{tabular}{|c|c|c|c|}
\hline Competency & Basic & Intermediate & Advanced \\
\hline Deixis & & & \\
\hline $\begin{array}{l}\text { Interpreters show } \\
\text { competence with } \\
\text { deixis when } \\
\text { interpreting a passage } \\
\text { with many voices by } \\
\text { role shifting effectively }\end{array}$ & $\begin{array}{l}\text { Actors are confused and } \\
\text { undifferentiated. }\end{array}$ & $\begin{array}{l}\text { Some actors are clearly } \\
\text { differentiated (such as } \\
\text { assistants and opponents), } \\
\text { while others are unclear } \\
\text { (such as the narrator } \\
\text { and the subject). }\end{array}$ & $\begin{array}{l}\text { All actors in the discourse } \\
\text { are clearly differentiated. }\end{array}$ \\
\hline
\end{tabular}




\begin{tabular}{|l|l|l|l|}
\hline Modality & & \\
\hline $\begin{array}{l}\text { Interpreters recreate } \\
\text { modality when } \\
\text { interpreting persua- } \\
\text { sive or argumentative } \\
\text { discourse by using } \\
\text { prosody (spoken } \\
\text { languages) and NMS } \\
\text { (sign languages) to } \\
\text { show relationships } \\
\text { between units of } \\
\text { information. }\end{array}$ & $\begin{array}{l}\text { insoctive. Interpreted } \\
\text { a list of information } \\
\text { without a purpose. }\end{array}$ & $\begin{array}{l}\text { Prosody/NMS is } \\
\text { sometimes effective. } \\
\text { Some parts of the } \\
\text { discourse are illustrated } \\
\text { with the appropriate } \\
\text { contours. }\end{array}$ & $\begin{array}{l}\text { Prosody/NMS is used } \\
\text { effectively. } \\
\text { Suprasegmental features } \\
\text { are used to clearly } \\
\text { indicate addition of } \\
\text { information, an } \\
\text { opposition to } \\
\text { information, and } \\
\text { examples. }\end{array}$ \\
\hline $\begin{array}{l}\text { Speech Acts } \\
\text { Interpreters create a } \\
\text { speech act in } \\
\text { consecutive } \\
\text { interpreting by } \\
\text { organizing their } \\
\text { utterance into } \\
\text { expected argumentative } \\
\text { structures. }\end{array}$ & $\begin{array}{l}\text { Argumentative } \\
\text { structures used are } \\
\text { those expected by } \\
\text { the source-language } \\
\text { culture. }\end{array}$ & $\begin{array}{l}\text { Argumentative } \\
\text { structures used are } \\
\text { sometimes those } \\
\text { expected by the } \\
\text { target-language } \\
\text { culture. }\end{array}$ & $\begin{array}{l}\text { Argumentative } \\
\text { structures used are } \\
\text { always those expected } \\
\text { by the target-language } \\
\text { culture. }\end{array}$ \\
\hline
\end{tabular}

\section{Conclusion}

This article has sought to identify some of the competencies needed in professional interpreting. It has demonstrated how the tendency to view the act of translation as a lexico-semantic exercise offers only a limited understanding, and has illustrated this point with a number of examples. It has proposed using discourse theory to create a more holistic understanding of interpreting, one that includes both the énoncé and the énonciation. It has explained some features of discourse that should be of particular interest to professional interpreters and, in so doing, has pointed the way for further applications of discourse theory. The article has demonstrated how assessment systems that focus uniquely on locating meaning at the lexical level are ultimately unsatisfying. And it has underlined the importance of instilling interpreter assessment with the kind of rigour evident in other kinds of assessment. Lastly, it has given an example of how discourse theory might inform the development of an actual assessment instrument.

Potential applications of discourse theory to professional interpreting have by no means been exhausted within the limited scope of these pages. Similarly, a great deal of work remains to be done in the development of rigorous interpreter assessment. Future research may concentrate on describing the full set of competenciesas regards both content and context-needed to perform to professional standards. Alternatively, it may begin to supply some much needed work on quality assurance in interpreter assessment, by focussing on measures of validity, reliability, equity, utility or comparability. 


\section{NOTES}

1. Research has for some time now indicated that visual and spatial tasks are processed in the right hemisphere of the brain, in a majority of right-handed people (Millar and Whitaker 1983). Consequently, there was early speculation that sign language processing differed from spoken language processing in its greater involvement of the right hemisphere (Ross 1983). However, subsequent research suggests that the two modes of language are processed in remarkably similar ways (Poizner, Klima and Bellugi 1987; Corina and Vaid 1994; Clifford 1999).

2. Ong gives the example of a storyteller in an oral culture who describes the action of the protagonist in an epic poem. The storyteller becomes so enthralled with his tale that he begins to use the first person to talk about the protagonist, as though he were recounting first-hand experiences. At the lexical level, there is nothing to distinguish the voice of the narrator from that of the hero, yet listeners do understand that there are two different voices.

2. Delisle underlines this causal relationship when he suggests that the French translator avoids the use of "et" in favour of a more idiomatic and transparent solution: "Achetez tout en faisant des économies."

2. Recent work in sign language studies has suggested that Non-Manual Signals (NMS) play a similar role in ASL. See Tennant and Gluszak Brown (1998).

2. A distinction is made between the words "deaf" (with a lower case letter) and "Deaf" (with an upper case letter). The former describes a medical condition or disability-the way the hearing world has traditionally viewed deafness. The latter, consistent with the way the Deaf view themselves, describes a community with its own institutions and culture, which centres around the use of a sign language like ASL.

\section{REFERENCES}

BARIK, H. C. (1971): "A Description of Various Types of Omissions, Additions and Errors in Translation Encountered in Simultaneous Interpretation" Meta, 16, pp. 199-210.

Bensimon, P. (1994): Traduction des figures de style dans un poème de Seamus Heaney, Unpublished manuscript.

Benveniste, É. (1971): Problems in General Linguistics, Miami, University of Miami Press.

Berger, M.-J. et M. Simon (1995): Programmation et évaluation en milieu scolaire: notes de cours, PED 3713 95/96, Université d'Ottawa, Unpublished manuscript.

Clifford, A. (1999): La préférence hémisphérique dans deux modes d'interprétation simultanée, unpublished master's thesis, Université Laval.

Cорроск, P. (1992): “Interpreting Discourse-Signs for the Future?, In Expanding Horizons: Proceedings of the Twelfth National Convention of the Registry of Interpreters for the Deaf, Silver Spring, MD, RID Publications.

Delisle, J. (1980): L'Analyse du discours comme méthode de traduction, Ottawa, Éditions de l'Université d'Ottawa.

Ducrot, O. (1980): Les échelles argumentives, Paris, Les Éditions de Minuit.

Eco, U. (1983): Lector in fabula: La cooperazione interpretativa nei testi narrativi, Milan, Bompiani.

Folkart, B. (1988): “Coherence and the Teaching of Translation," Meta, 33, pp. 142-155.

Gipps, C. V. (1994): Beyond Testing: Towards a Theory of Educational Assessment, London, Falmer Press.

Haladyna, T. M. (1994): “A Research Agenda for Licensing and Certification Testing Validation Studies," Evaluation \& the Health Professions, 17-2, pp. 242-256.

Halliday, M. A. K. (1970): A Course in Spoken English: Intonation, London, Oxford UP.

LaDucA, A. (1994): "Validation of Professional Licensure Examinations: Professions Theory, Test Design, and Construct Validity," Evaluation \& the Health Professions, 17-2, pp. 178-197.

Linn, R. L., E. Baker and S. Dunbar (1991): “Complex, Performance-Based Assessments: Expectations and Validation Criteria," Educational Researcher, 20-8, pp. 15-21.

McDAniel, E. (1994): Understanding Educational Measurement, Madison WI, WCB Brown \& Benchmark. 
Millar, J. M. and H. A. Whitaker (1983): “The Right Hemisphere's Contribution to Language: A Review of the Evidence from Brain Damaged Subjects," Language Functions and Brain Organization (S. Segalowitz, ed.), New York, Academic Press.

Mindess, A. (1995): "Intercultural Communication for Sign Language Interpreters," A Celebration of the Profession: Proceedings of the Fourteenth National Convention of the Registry of Interpreters for the Deaf, Silver Springs MD, RID Publications.

Nord, C. (1997): Translating as a Purposeful Activity: Functionalist Approaches Explained, Manchester UK, St. Jerome Publishing.

O'grady, W. and M. Dobrovolsky (1992): Contemporary Linguistic Analysis: An Introduction, Toronto, Copp Clark Pitman.

Resnick, L. B. and D. P. (1992): "Assessing the Thinking Curriculum: New Tools for Educational Reform," Changing Assessments: Alternative Views of Aptitude, Achievement and Instruction (B. R. Gifford and M. C. O'Connor, eds), Boston, Kluwer Academic Publishers.

Ross, P. (1983): "Cerebral Specialization in Deaf Individuals," Language Functions and Brain Organization (S. Segalowitz, ed.), New York, Academic Press.

Saussure, F. de (1969): Cours de linguistique générale, Paris, Payot.

Seleskovitch, D. et M. Lederer (1984): Interpréter pour traduire, Paris, Didier Érudition.

Smith, I. L. and R. K. Hambleton (1990): "Content Validity Studies of Licensing Examinations," Educational Measurement: Issues and Practices, 9-4, pp. 7-10.

TAYLOR, M. (1994): Interpretation skills: English to American Sign Language, Edmonton, Interpreting Consolidated.

Tennant, R. and M. Gluszak Brown (1998): The American Sign Language Handshape Dictionary, Washington D.C., Clerc Books and Gallaudet University Press.

Van Hoof, H. (1989): Traduire de l'anglais, Paris, Duculot.

Zangwill, O. L. (1967): "Speech and the Minor Hemisphere," Acta Neurologica et Psychiatrica Belgica, 67, pp. 1013-1020. 